\title{
SUICIDE ATTEMPTS AND ITS OUTCOIME : ELDERLY VS LOWER AGE GROUPS
}

KEY WORDS: Suicide, Elderly, Completed Suicide, Outcome

\section{N Padmaja}

\section{P Krishna}

Bharadwaj*
First Author, Assistant Professor, Department Of General Medicine, SV Medical College,Tirupati.

Senior Resident, Department Of General Medicine, SV Medical College, Tirupati. *Corresponding Author

BACKGROUND:The number of suicide attempts in developing countries has been increasing progressively, as in the west. There is also a global trend toward increased suicide in late life, mainly in men. It is important to note that much of the data on suicidal behaviour is based on information obtained from developed western countries.

This study is to detect any differences in outcome between elderly and lower age groups.

METHODS: Retrospective, Comparative study based on records of patients admitted in a tertiary care hospital over a period of one year from August 2016 to July 2017. Primary outcome studied was death.

RESULTS AND CONCLUSION: Out of 778 suicide attempters studied, 58 were above 60 yrs of age. The ratio of male to female suicides in elderly was 2:1, whereas in lower age groups, it was almost equal in both the sexes. The ratio of completed suicide to attempted suicide was found to be 1:5, which is triple the ratio of 1:15 in lower age groups. This reflects death due to added co-morbidities in elderly. This Incidence is very high and can be attributed to disintegration of joint families in the recent era.

\section{INTRODUCTION:}

The number of suicide attempts in the developing countries has been increasing progressively as in the west(1). In India, a suicide attempt was until recently a punishable legal offence, hence it is either covered up or labelled as accidental to avoid social stigma and legal consequences(2). This lead to lack of accurate data to draw projections for meeting the burden on medical services.

There is a global trend toward increased suicide in late life, but its prevalence is low in india may be because the aged are well integrated and respected in the family. Significant differences in attempting rate and recovery has been noted globally among elderly and other ages. It is also important to note that much of the data is based on information obtained from western world.

The exact magnitude of problem is difficult to recognise in India because of inefficient civil registration systems, non report of deaths and social consequences of suicide. The present study was conducted in order to determine the occurence of suicide attempts and its outcome in elderly population attending a tertiary care hospital.

AIM :

To determine the incidence of suicide attempts and its outcome in elderly and to compare the same in lower age groups.

\section{OBJECTIVES:}

1. To determine the incidence of suicide attempts in elderly among others.

2. To note any gender differences in suicide attempts and its outcome.

3. To detect any differences in outcome between elderly and lower age groups.

\section{MATERIALS AND METHODS:}

Retrospective, Comparative study based on records of patients admitted in a tertiary care hospital over a period of 1 year from August 2016 to July 2017. Patients aged $\geq 60$ yrs were considered as elderly and the outcome studied was death. The data is collected and analysed in SPSS software and Mac Os Numbers version 3.6.2.

\section{RESULTS:}

Records of all patients with suicide attempts admitted in acute medical care and medical wards in Sri Venkateswara Ramnarain Ruia Government General Hospital, Tirupati from August 2016 to July 2017 were analysed.

A total of 778 patients attempted suicide during the study period. Among them 58 (7\%) patients were aged 60 years and above, the rest $720(93 \%)$ patients were aged below 60 years. In the age group < 60 yrs, $381(53 \%)$ patients were males and $339(47 \%)$ were females. In the Elderly group aged 60 and above, Males are $40(69 \%)$ and females are $18(31 \%)$ in number. Although Males predominate over females in attempting suicide, there is $16 \%$ decrease in female attempters in elderly population. This is shown in table 1.

\begin{tabular}{|l|l|l|l|}
\hline \multicolumn{4}{|c|}{ Table 1 : Sex distribution in Both groups } \\
\hline & Males & Females & Total \\
\hline Age < 60 years & $381(53 \%)$ & $339(47 \%)$ & 720 \\
\hline Aged 60 and above & $40(69 \%)$ & $18(31 \%)$ & 58 \\
\hline
\end{tabular}

Out of 720 attempters aged < 60 yrs, $49(6.8 \%)$ patients died and in 58 elderly attempters, $12(20.68 \%)$ patients succumbed to death. The ratio of deaths among attempts in elderly is $1: 5$ which is very high compared to ratio of $1: 15$ in lower age groups. Outcome differences is shown in table 2. This shows increased mortality in elderly compared to lower age groups and this difference is statistically significant with a $\mathrm{p}$-value of $0.000154(<0.05)$.

\begin{tabular}{|c|c|c|c|}
\hline \multicolumn{4}{|c|}{ Table 2: Outcome in both groups } \\
\hline & Survival & Death & Total \\
\hline Age < 60 years & $671(93.2 \%)$ & $49(6.8 \%)$ & 720 \\
\hline Aged 60 and above & $46(79.32 \%)$ & $12(20.68 \%)$ & 58 \\
\hline
\end{tabular}

Out of 49 deaths in lower age group, 31 are males and 18 are females. Among 12 deaths in elderly, 7 are males and 5 patients are females. Sex distribution of Outcome is shown in the Table 3 .

\begin{tabular}{|c|c|c|c|}
\hline \multicolumn{4}{|c|}{ Table 3 : Sex distribution of Outcome in both groups } \\
\hline Death & Males & Females & Total \\
\hline Age < 60 years & $31(63.2 \%)$ & $18(36.8 \%)$ & 49 \\
\hline Aged 60 and above & $7(58.3 \%)$ & $5(41.7 \%)$ & 12 \\
\hline
\end{tabular}

Among 40 elderly males who attempted suicide, 33 (82.5\%) survived and only $7(17.5 \%)$ died.Whereas, among 18 elderly females who attempted suicide, only $13 \quad(72.2 \%)$ survived and the rest $5(27.8 \%)$ died. 1 in 4 elderly female patients who 
attempted suicide died, but in males 1 in 6 elderly attempters died. This shows increased mortality in elderly females than in males attempting suicides. But this increased mortality is not statistically significant as $p$-value is 0.371 ( $p>0.05)$. This shown in table 4.

\begin{tabular}{|c|c|c|c|}
\hline \multicolumn{4}{|c|}{ Table 4 : Outcome differences based on gender in } \\
Elderly
\end{tabular}

Out of 381 male suicide attempters in lower age group, 350 patients survived and 30 patients died. Whereas 18 patients died among 339 female suicide attempters in the lower age group. There is no statistically significant difference in outcomes based on gender as p-value is $0.13(>0.05)$. This is shown in the table 5 .

\begin{tabular}{|c|c|c|c|}
\hline \multicolumn{4}{|c|}{ Table 5 : Outcome differences based on gender in } \\
Lower age group \\
\hline Lower Age group & Survived & Death & Total \\
\hline Males & $350(91.8 \%)$ & $31(8.2 \%)$ & 381 \\
\hline Females & $321(94.7 \%)$ & $18(5.3 \%)$ & 339 \\
\hline
\end{tabular}

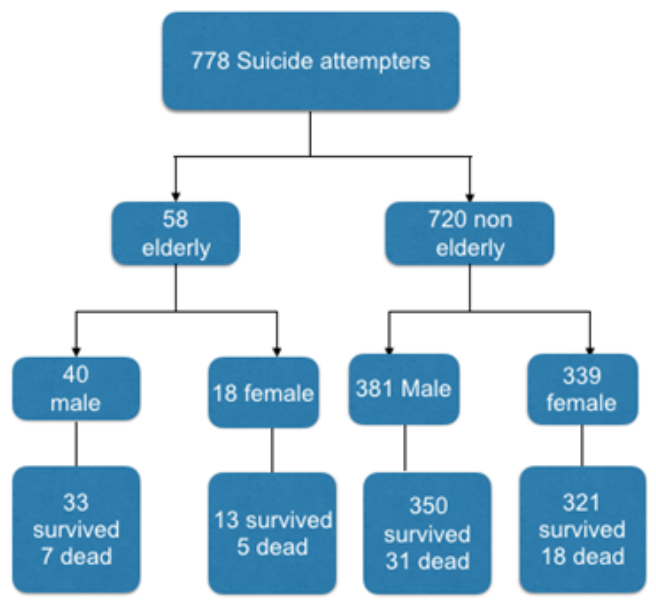

\section{Summary of observations is shown in Figure 1 below}

\section{Figure 1: Summary of Observations}

\section{DISCUSSION:}

In our study, 58 among 778 attempters were elderly. Rao AV and Madhavan T studied 6312 suicide attempters over a period of 5 years in 1980s, where only 47 were above 60 yrs of age(3). This reveals increasing suicidal tendency in elderly in our country over these couple of decades.

In this study 1 in 5 elderly attempters died which 3 times higher than in lower age groups. In Rao AV and Madhavan T study (3), the ratio of completed suicide to attempted suicide in India is about 1:7 in the elderly, which is double the ratio of $1: 15$ in lower age groups.

Male preponderance is noted in both elderly and lower age groups in our study. Globally, attempted suicide is commoner in women and completed suicide is commoner in men. In India, Our study is consistent with Gururaj $\mathbf{G}$ and Isaac MK study who found a higher incidence of suicide in men than in women(4). The male: female suicide ratio was 1.78 in India in 2008 and 2009. But, Benerjee $\mathrm{G}$ et al study showed females are more vulnerable for suicides(5).

Although Male preponderance among attempters is noted in our study in both elderly and lower age groups, death rate is more in female elderly than males. But There is no statistically significant difference in outcome based on gender in both elderly and lower age groups. This is consistent with Gururaj G and Isaac MK study which showed greater female suicidal completion in India(4).

\section{CONCLUSIONS:}

Incidence of suicide attempts in elderly increased in past two decades and this can be attributed to change in family structure during recent decades, with more people moving out of joint and extended families into nuclear family structures and increasing life expectancy. The ratio of completed suicide to attempted suicide in elderly is three times than in lower age groups reflecting significant comorbidities in elderly.

This study shows much emotional care is needed to protect our elderly and proper identification and counselling must be given to prevent these attempts in geriatric clinics and it is the time to improve geriatric health care in our country.

\section{LIMITATIONS:}

As it is retrospective study done in a single tertiary care hospital, actual burden and magnitude of the problem couldn't be made out. Socio-cultural, marriage and relationship aspects were not included in this study. Modes of suicide and its effect on outcome in either age groups were not included in this study.

\section{REFERENCES}

1. Deaths, A. Suicides in India.(2007). New Delhi: Ministry of Home Affairs, Government of India; 2009. National Crime Records Bureau.

2. World Health Organization. (2011). Suicide rates per 100,000 by country, year and sex (Table) Most recent year available; as of 2011 . Geneva: Switzerland: World Health Organization,(Retrieved August 7, 2012, http://www. who. int/mental health/prevention/suicide_rates/en/index.html).

3. Rao, A. V., \& Madhavan, T. (1983). Depression and suicide behaviour in the aged.Indian Journal of Psychiatry, 25(4), 251.

4. Gururaj, G., \& Isaac, M. K. (2001). Epidemiology of suicides in Bangalore. National Institute of Mental Health \& Neuro Sciences.

5. Banerjee, G., Nandi, D. N., Nandi, S., Sarkar, S., Boral, G. C., \& Ghosh, A. (1990) The vulnerability of Indian women to suicide a field-study. Indian Journal of Psychiatry, 32(4), 305. 